\title{
$\beta 2$-adrenergic receptor expression and the effects of norepinephrine and propranolol on various head and neck cancer subtypes
}

\author{
SOON YOUNG KWON ${ }^{1}$, KYUNG JU CHUN ${ }^{2}$, HONG KWON KIL ${ }^{2}$, NARAE JUNG ${ }^{2}$, HYUN-AH SHIN ${ }^{2}$, \\ JEON YEOB JANG ${ }^{3}$, HYO GEUN CHOI ${ }^{4}$, KYOUNG-HO OH ${ }^{1}$ and MIN-SU KIM ${ }^{2}$ \\ ${ }^{1}$ Department of Otorhinolaryngology-Head and Neck Surgery, Korea University Ansan Hospital, \\ Korea University College of Medicine, Ansan, Gyeonggi-do 15355; ${ }^{2}$ Department of Otorhinolaryngology-Head and \\ Neck Surgery, CHA Bundang Medical Center, CHA University School of Medicine, Seongnam, Gyeonggi-do 13496; \\ ${ }^{3}$ Department of Otorhinolaryngology-Head and Neck Surgery, Ajou University Hospital, Ajou University College of Medicine, \\ Suwon, Gyeonggi-do 16499; ${ }^{4}$ Department of Otorhinolaryngology-Head and Neck Surgery, Hallym University \\ Sacred Heart Hospital, Hallym University College of Medicine, Anyang, Gyeonggi-do 14068, Republic of Korea
}

Received March 14, 2021; Accepted August 27, 2021

DOI: $10.3892 / 01.2021 .13065$

\begin{abstract}
The present study aimed to investigate expression of $\beta 2$-adrenergic receptor (AR), the effect of the stress-related neurotransmitter norepinephrine (NE) on cell viability, proliferation and the therapeutic effect of propranolol, which is a typical $\beta$-blocker in various type of head and neck cancers for the first time. The $\beta 2$-AR expression was investigated using immunohistochemistry and an immunoreactive scoring (IRS) system in 57 different head and neck cancer specimens, and reverse transcriptase-polymerase chain reaction and western blotting in four head and neck cancer cell lines (HNCCLs). Cell viability and proliferation assays were performed using $0,1,5$ and $10 \mu \mathrm{M}$ of $\mathrm{NE}$ and $1 \mu \mathrm{M}$ of propranolol in four HNCCLs. The expression of $\beta 2$-AR was positive in the majority of head and neck cancer tissues $(55 / 57,96.5 \%)$; however, it was significantly higher in oral cavity cancer than in pharyngeal cancer (median IRS: 9 vs. 3; P<0.001). All HNCCLs exhibited $\beta 2-A R$ expression, with a higher expression level detected in the oral cavity cancer cell line than in the others. NE stimulated viability (oral cavity, 206\%; larynx, 156\%; pharynx, 130\%; nasal cavity, 137\%; $10 \mu \mathrm{M} \mathrm{NE})$ and proliferation $(124,176$, 131 and $127 \%$, respectively) in a dose-dependent manner in all HNCCLs. Conversely, propranolol attenuated such viability (55, 42, 18 and 22\%, respectively) and proliferation (22, 40, 61 and $48 \%$, respectively). In conclusion, the viability and
\end{abstract}

Correspondence to: Professor Min-Su Kim, Department of Otorhinolaryngology-Head and Neck Surgery, CHA Bundang Medical Center, CHA University School of Medicine, 59 Yatap-ro, Bundang, Seongnam, Gyeonggi-do 13496, Republic of Korea

E-mail: abraxas8109@gmail.com

Key words: norepinephrine, adrenergic receptor, adrenergic $\beta$-antagonists, head and neck neoplasms, stress proliferation of various head and neck cancers may be directly stimulated by stress and this may be attenuated by $\beta$-blockers.

\section{Introduction}

Head and neck cancers occur in the oral cavity, larynx, pharynx and nasal cavity. With $\sim 600,000$ new patients annually, head and neck cancers rank seventh in the global incidence rate of malignant tumors. However, this cancer type is difficult to detect in the early stages; thus, patients are often diagnosed in the late stage. The 5-year overall survival rate is $54.7-65.9 \%$, which has not significantly improved over the years (1). Furthermore, head and neck cancer surgery is relatively time consuming and difficult. Therefore, performing multiple cancer surgeries in a day is difficult. Consequently, often surgery cannot be performed early, even after diagnosis. Notably, when surgeons perform an operation more than a month after the final diagnosis, they often experience a considerably more advanced lesion than at the time of diagnosis, especially in patients with advanced head and neck cancer (2).

Meanwhile, $\beta$-blockers have been widely used for the treatment of cardiovascular diseases or anxiety disorders. They may also exert cancer-treating effects (3-8). $\beta$-blockers inhibit the sympathetic actions of stress-related catecholamine hormones, such as norepinephrine (NE) (9). This sympathetic mechanism occurs via $\beta$-adrenergic receptors $(\beta$-AR), reflecting that $\beta$-AR is abundant in the cancer tissues $(9,10)$. We hypothesized that $\beta$-blockers can slow tumor progression prior to head and neck cancer surgery, which would confer a great clinical benefit. Additionally, after being diagnosed with head and neck cancer, patient anxiety is often amplified. Thus, $\beta$-blockers could also help the patients psychologically before surgery.

According to some experimental evidence, various cancer cells express $\beta 2-\mathrm{ARs}$, and NE may influence carcinogenesis through these receptors $(8,11)$. During acute or chronic stress, the sympathetic adrenal medullary axis is activated, resulting in NE synthesis. Via $\beta$-ARs, NE stimulates cancer growth by 
upregulating proangiogenic factors, such as vascular endothelial growth factor (VEGF) (7). Furthermore, prostaglandin E2 synthesis is also augmented because of sustained adrenergic signaling and NE-mediated phosphatase 1 overexpression (12). However, evidence from epidemiological and clinical studies remains inconclusive. In a recent systematic review study about the effect of $\beta$-blockers on cancer recurrence and survival, melanoma was associated with reduced recurrence [hazard ratio (HR), 0.03; 95\% confidence interval (CI) 0.01-0.17] and increased survival (HR, 0.04; 95\% CI, 0.00-0.38). However, endometrial cancer showed increased recurrence (HR, 1.40; 95\% CI, 1.10-1.80) as well as reduced survival (HR, 1.50; 95\% CI, 1.12-2.00). In another study, non-selective $\beta$-blocker was associated with improved recurrence and survival in melanoma and ovarian cancer, but reduced survival in lung cancer (6).

Nevertheless, the effect of $\beta$-blockers on head and neck cancer has remained poorly investigated. A national cohort study in Taiwan demonstrated that $\beta$-blockers could reduce cancer development risk in head and neck cancer (HR, 0.58 , 95\% CI, 0.35-0.95) (13). Conversely, a study on a Korean population observed that $\beta$-blocker administration was associated with decreased survival in head and neck cancer (14). The majority of research has focused on assessing the association between NE and $\beta$-blockers in oral cavity cancers $(11,15-20)$. Other than in oral cavity cancer, only one other study regarding nasopharyngeal cancer was identified (21). Therefore, the effect of NE and $\beta$-blocker needs to be examined in various head and neck cancers, including laryngopharyngeal cancer.

\section{Materials and methods}

$\beta 2$-adrenergic receptor expression in head and neck cancer specimens. In total, 57 head and neck cancer tissue specimens were obtained from surgically diagnosed patients (median age, 65 years; age range, 33-89 years) by the Department of Pathology in CHA Bundang Medical Center between January 2009 and December 2018. The institutional review board of the CHA Medical Center reviewed and approved our study (IRB approval no. NON2020-003-002). Clinical staging was based on the TNM staging system of the Union for International Cancer Control, 8th edition (22). The specimens were fixed in $10 \%$ neural buffered formalin for $24 \mathrm{~h}$ at $4^{\circ} \mathrm{C}$ and embedded in paraffin. Tissue blocks were divided into $3-\mu \mathrm{m}$ sections for hematoxylin and eosin staining and immunohistochemistry of $\beta 2-A R$. All cases were diagnosed as squamous cell carcinoma. Patients with neuroendocrine cancer, sarcoma or preoperative radiotherapy/chemotherapy were excluded. Tissue microarray sections were dewaxed in xylene, rehydrated in alcohol and immersed in 3\% hydrogen peroxide for $40 \mathrm{~min}$ at room temperature. Antigens were retrieved by heating $\left(100^{\circ} \mathrm{C}\right)$ each section in $10 \mathrm{mmol} / \mathrm{l}$ of sodium citrate buffer for $10 \mathrm{~min}$. After being rinsed thrice in phosphate-buffered saline (PBS), each section was incubated with rabbit polyclonal antibodies to $\beta 2-\mathrm{AR}$ (cat. no. ab61778, 1:100; Abcam) for $18 \mathrm{~h}$ at $4^{\circ} \mathrm{C}$. Then, they were diluted and washed thrice in PBS and incubated with horseradish peroxidase (HRP)-labeled rabbit anti-mouse immunoglobulin for $30 \mathrm{~min}$ at room temperature. Subsequently, samples were washed thrice and stained with diaminobenzidine solution for
$5 \mathrm{~min}$ at room temperature to visualize peroxidase activity. For negative controls, primary antibodies were replaced with PBS. For the positive control, normal upper eyelid muscles for 3 patients underwent upper eyelid surgery for ptosis correction were used. They were 3 females (median age, 58; range, 51-69). The tissue blocks were stored by the Department of Pathology in CHA Bundang Medical Center for other research purposes after IRB approval. The expression of $\beta 2-A R$ protein was assessed by cytoplasmic staining of the cancer cells. To stratify $\beta 2-\mathrm{AR}$ expression, the immunoreactive score (IRS) system was used because of marked intratumoral heterogeneous expression in proportion and intensity in cancer tissues. The IRS system is calculated by multiplying the percentage of positive cells $(0$, no positive cells; $1,<10 \%$ of positive cells; $2,10-50 \% ; 3,51-80 \% ; 4,>80 \%)$ and the intensity of the staining $(0$, no color reaction; 1 , mild reaction; 2 , moderate reaction; 3 , intense reaction). Thus, the IRS result is between 0 (no staining) and 12 (maximum staining), categorized into negative (0-1), mild (2-3), moderate (4-8), and strongly positive $(9-12,23)$. A light microscope (Olympus System Microscope Model BX43; magnification, x200 and x400) was used to obtain images. The intensity of the staining was determined by using QuPath version 2.0 freeware (24). It was measured as the optical density (OD). The staining vectors for all images were estimated automatically before OD measurement. The samples with OD $<0.2$ were considered negative (score, 0), OD ranking 0.2-0.4 was considered mild (score, 1), OD ranking 0.4-0.6 was considered moderate and OD >0.6 was considered intense (score, 3 ).

Human papilloma virus (HPV) in head and neck cancer specimens. DNA was extracted from the specimens using a DNA isolation kit (ISOLATE II Genomic DNA kit; Meridian Bioscience, Inc.). HPV 16/18- deoxyribonucleic acid (DNA) was amplified by polymerase chain reaction (PCR) and nested PCR assays using two pairs of primers to identify HPV16/18 and the HPV16/18 regions of the L1 gene and DNA polymerase (DreamTaq Green; Thermo Fisher Scientific, Inc.). The PCR primer sequences used for each gene were as follows: HPV 16 forward, 5'-ACCCAGTATAGCTGACAGT-3' and reverse, 5'-CTCGTTTATAATGTCTACACA-3'; and HPV 18 forward, 5'-ATAGCAATTTTGATTTGTC-3' and reverse, 5'-AAACTCATTCCAAAATATG-3'. During the first PCR, the amplification process included 35 cycles with pre-denaturation at $95^{\circ} \mathrm{C}$ for $4 \mathrm{~min}$, denaturation at $95^{\circ} \mathrm{C}$ for $30 \mathrm{sec}$, annealing at $55^{\circ} \mathrm{C}$ for $30 \mathrm{sec}$, first elongation at $72^{\circ} \mathrm{C}$ for $1 \mathrm{~min}$ and $30 \mathrm{sec}$ and additional elongation at $75^{\circ} \mathrm{C}$ for $10 \mathrm{~min}$. Using the same reagents, the second PCR was performed on the first PCR aliquots. Nested PCR results were analyzed by $2 \%$ agarose gel electrophoresis. During the second PCR, the amplification process was conducted with initial denaturation at $95^{\circ} \mathrm{C}$ for $4 \mathrm{~min}$, denaturation at $94^{\circ} \mathrm{C}$ for $30 \mathrm{sec}$, annealing at $56.4^{\circ} \mathrm{C}$ for $30 \mathrm{sec}$, first elongation at $75^{\circ} \mathrm{C}$ for $1 \mathrm{~min}$ and $30 \mathrm{sec}$ and additional elongation at $72^{\circ} \mathrm{C}$ for $10 \mathrm{~min}$. DNA visualization was conducted using machine electrophoresis on the Gel Doc EZ System (Bio-Rad Laboratories, Inc.).

Cell lines and culture conditions. The following four different head and neck cancer cell lines (HNCCLs) were investigated: oral cavity (YD-10B, tongue), larynx (SNU-1066, glottis), 
pharynx (SNU-1041) and nasal cavity (RPMI-2650) cancers. They were purchased from the Korean Cell Line Bank and were maintained in a mixture of Dulbecco's modified Eagle's medium (DMEM; Thermo Fisher Scientific, Inc.) and Ham's nutrient mixture F12 (Thermo Fisher Scientific, Inc.) at a 3:1 ratio. They were supplemented with $10 \%$ fetal bovine serum (FBS; Thermo Fisher Scientific, Inc.) and $50 \mathrm{U} / \mathrm{ml}$ concentration of penicillin at $37^{\circ} \mathrm{C}$ in $5 \% \mathrm{CO}_{2}$.

Reverse transcription-quantitative (RT-q) PCR. Total RNA was isolated using TRIzol reagent (Ambion; Thermo Fisher Scientific, Inc.). For reverse transcription, the AccuPower ${ }^{\circledR}$ RT premix cDNA synthesis kit was used according to the manufacturer's instructions (Bioneer Corporation). For RT-PCR, $1 \mu \mathrm{g}$ cDNA products were amplified using SYBR Green Supermix (Bio-Rad Laboratories, Inc.). For SYBR Green assays, $\beta 2-\mathrm{AR}$ and RPS18 primers (for $18 \mathrm{~S}$ rRNA) were used. The PCR primer sequences used for each gene were as follows: $\beta 2$-AR forward, 5'-TTAGCCAGGTGGAGCAGGATG-3' and reverse, 5'-GCCTAACGTCTTGAGGGCTTTG-3'; and RPS18 forward, 5'-GCAGAATCCACGCCAGTACAAG-3' and reverse, 5'-GCTTGTTGTCCAGACCATTGGC-3'. Fluorescence was detected with the CFX Connect ${ }^{\mathrm{TM}}$ Real-Time PCR Detection System (Bio-Rad Laboratories, Inc.). All values were standardized using the $2^{-\Delta \Delta \mathrm{Cq}}$ method (25). Moreover, the level of $\beta 2$-AR messenger RNA (mRNA) expression was normalized to $18 \mathrm{~S}$ rRNA. PCR conditions were: Initial activation at $95^{\circ} \mathrm{C}$ for $5 \mathrm{~min}$, denaturation at $94^{\circ} \mathrm{C}$ for $40 \mathrm{sec}$, annealing at $60^{\circ} \mathrm{C}$ for $30 \mathrm{sec}, 35$ cycles of extension at $72^{\circ} \mathrm{C}$ for $60 \mathrm{sec}$ and final elongation at $72^{\circ} \mathrm{C}$ for $8 \mathrm{~min}$.

Protein extraction and western blot analysis. Cell lysates were isolated by adding PRO-PREP ${ }^{\mathrm{TM}}$ protein extraction solution (Intron Biotechnology, Inc.) containing various protease inhibitors, such as phenylmethylsulfonyl fluoride, ethylenediamine tetraacetic acid, pepstatin A, leupeptin and aprotinin. Total protein concentration was determined by using a Pierce BCA Protein Assay kit (Thermo Fisher Scientific, Inc.). Furthermore, $40 \mu \mathrm{g}$ of protein/lane was resolved using $10 \%$ sodium dodecyl sulfate-poly acrylamide gel electrophoresis and then transferred to a nitrocellulose membrane. The nitrocellulose membranes were blocked in $5 \%$ milk/Tris-buffered saline with $0.1 \%$ Tween-20 (TBS-T) at $25^{\circ} \mathrm{C}$ for $1 \mathrm{~h}$ and then incubated with $\beta 2$-AR primary antibodies overnight at $4^{\circ} \mathrm{C}$. The primary antibody was the anti- $\beta 2$-AR rabbit monoclonal antibody (cat. no. ab182136; Abcam) at a 1:1,000 dilution. After being washed in TBS-T buffer, the membrane was incubated with HRP-conjugated secondary antibodies for $1 \mathrm{~h}$. The secondary antibody was goat anti-rabbit IgG (cat. no. ab97051; Abcam) at 1:20,000 dilution. The internal control used was $\beta$-actin. The primary and secondary antibody used for $\beta$-actin were as follows: anti- $\beta$-actin mouse antibody (cat. no. sc-47778; Santa Cruz Biotechnology, Inc.), goat anti-mouse IgG antibody conjugated to HRP (cat. no. GTX213111-01; GeneTex, Inc.). The immunoreactive protein bands were visualized with a chemiluminesence solution enhanced with the LimiFlash ${ }^{\mathrm{TM}}$ Ultima Chemiluminescent substrate, HRP System (Energenesis Biomedical Co., Ltd.). ImageJ version 1.51 software (National Institutes of Health) was used for densitometry.
Cell viability and proliferation assays. HNCCLs were seeded in 96-well plates, with $1.5 \times 10^{4}$ cells (YD-10B), $2.5 \times 10^{4}$ cells (SNU-1066) and $2 \times 10^{4}$ cells (SNU-1041 and RPMI-2650) per well. They were cultured in RPMI-1640 (Welgene, Inc.) supplemented with $0.1 \%$ FBS and then treated with $0,1,5$ or $10 \mu \mathrm{M}$ concentrations of NE (MilliporeSigma) and $1 \mu \mathrm{M}$ of propranolol (MilliporeSigma). For blocking, $1 \mu \mathrm{M}$ propranolol was added to the HNCCLs $1 \mathrm{~h}$ before adding $10 \mu \mathrm{M}$ of NE. The treated HNCCLs were then incubated at $37^{\circ} \mathrm{C}$ for $24 \mathrm{~h}$. The concentrations of $\mathrm{NE}$ and propranolol were selected based on references describing similar protocols $(18,21,26,27)$. Furthermore, cell viability and proliferation were evaluated using the enhanced cell viability assay EZ-CYTOX (DoGen Bio Co., Ltd.) and the Cytoselect ${ }^{\mathrm{TM}}$ BrdU cell proliferation enzyme-linked immunosorbent assay kits (cat. no. CBA-251; Cell Biolabs, Inc.). Each experiment was performed thrice independently. The results are expressed as the mean \pm standard error of the mean of three replicates.

Statistical analysis. Among the variables, significantly associated clinical factors were identified using the Mann-Whitney U test, Kruskal-Wallis test and Bonferroni's method. Significant changes in cell viability and proliferation assays were assessed by Kruskal-Wallis along with a post hoc test (Mann-Whitney $\mathrm{U}$ test with Bonferroni's method). $\mathrm{P}<0.05$ was considered to indicate a statistically significant difference. All statistical data were analyzed using the SPSS version 22.0 software (IBM, Corp.).

\section{Results}

Expression of $\beta 2-A R$ in head and neck cancer specimens and clinical factors. Table I summarizes the demographics of 57 patients with head and neck cancer. All patients displayed $32-\mathrm{AR}$ expression, except for two patients with pharyngeal cancer $(55 / 57 ; 96.5 \%)$. The mean IRS of $\beta 2$-AR expression was moderately positive (mean \pm standard deviation, $6.63 \pm 3.30$ ), with no significant differences in relation to sex, $\mathrm{T}$ stage, $\mathrm{N}$ stage, HPV status, and overall stages. However, it was significantly associated head and neck cancer subsites ( $\mathrm{P}=0.031$; Table I). In the post-hoc analysis, oral cavity cancer $(\mathrm{P}=0.023)$ had a significantly higher IRS of $\beta 2$-AR expression than pharyngeal cancer (Table II and Fig. 1).

Expression of $\beta 2-A R$ at the $m R N A$ and protein levels in HNCCLs. All HNCCLs showed the mRNA and protein expression of $\beta 2$-AR. Especially, mRNA expression of $\beta 2$-AR was high in an oral cavity cancer cell line (Fig. 2A). In western blot analysis, its protein expression was also strong in the same cell line (Fig. 2B and C).

Cell viability and proliferation of HNCCLs by NE and propranolol. The viability and proliferation of all cancer cells were induced by NE in a dose-dependent manner. These differences were all statistically significant except for in pharyngeal cancer (Figs. 3 and 4). Following post hoc analysis, the cell viability and proliferation in the $10 \mu \mathrm{M}$ of NE group were significantly higher compared with the $0 \mu \mathrm{M}$ of NE group. The amplified cell viability and proliferation 
Table I. Demographics of patients with head and neck cancer $(n=57)$ and analysis of immunoreactive scores in immunohistochemistry.

\begin{tabular}{|c|c|c|c|}
\hline Variable & Value & IRS, median (Q1-Q3) & P-value \\
\hline Median age, years (Q1-Q3) & $65(58-75)$ & $9(0-12)$ & \\
\hline Sex & & & 0.250 \\
\hline Male & $52(91.2 \%)$ & $9(4-9)$ & \\
\hline Female & $5 \quad(8.8 \%)$ & $4(3-6)$ & \\
\hline Subsite & & & 0.031 \\
\hline Oral cavity & $22(38.6 \%)$ & $9(6-9)$ & \\
\hline Larynx & $16(28.1 \%)$ & $9(4-9)$ & \\
\hline Pharynx & $11(19.3 \%)$ & $3(2-8)$ & \\
\hline Nasal cavity & $8(14.0 \%)$ & $9(6-9)$ & \\
\hline T stage & & & 0.562 \\
\hline $\mathrm{T} 1$ & $25(43.9 \%)$ & $9(3-9)$ & \\
\hline $\mathrm{T} 2$ & $15(26.3 \%)$ & $8(4-9)$ & \\
\hline $\mathrm{T} 3$ & $6(10.5 \%)$ & $6(3-6)$ & \\
\hline $\mathrm{T} 4$ & $11(19.3 \%)$ & $9(4-9)$ & \\
\hline N stage & & & 0.374 \\
\hline N0 & $34(59.6 \%)$ & $9(4-9)$ & \\
\hline $\mathrm{N} 1$ & $6(10.5 \%)$ & $3(2-9)$ & \\
\hline $\mathrm{N} 2$ & $17(39.8 \%)$ & $9(4-9)$ & \\
\hline HPV status & & & 0.186 \\
\hline Positive & $13(22.8 \%)$ & $6(3-9)$ & \\
\hline Negative & $44(77.2 \%)$ & $9(4-9)$ & \\
\hline Stage & & & 0.533 \\
\hline I & $22(38.6 \%)$ & $9(4-9)$ & \\
\hline II & $6(10.5 \%)$ & $9(6-9)$ & \\
\hline III & $7(12.3 \%)$ & $6(2-9)$ & \\
\hline IV & $22(38.6 \%)$ & $9(4-9)$ & \\
\hline
\end{tabular}

Table II. Demographics of patients with head and neck cancer $(n=57)$ and analysis of immunoreactive scores in immunohistochemistry.

\begin{tabular}{llr}
\hline Variable (median, Q1-Q3) & Pairwise variable (median, Q1-Q3) & P-value \\
\hline Oral cavity (9, 6-9) & Larynx $(9,4-9)$ & 0.990 \\
& Pharynx (3, 2-8) & 0.023 \\
& Nasal cavity (9, 6-9) & 0.904 \\
Larynx $(9,4-9)$ & Pharynx (3, 2-8) & 0.066 \\
Pharynx $(3,2-8)$ & Nasal cavity (9, 6-9) & 0.975 \\
& Nasal cavity $(9,6-9)$ & 0.309 \\
\hline
\end{tabular}

were significantly inhibited by propranolol treatment in all cancer types (Figs. 3 and 4).

\section{Discussion}

To the best of the authors' knowledge the present study was the first to investigate and compare $\beta 2$-AR expression in various head and neck cancers. Most head and neck cancer tissues expressed $\beta 2$-AR moderately. In addition, mRNA and protein expression levels of $\beta 2-\mathrm{AR}$ were detected in all HNCCLs. Notably, $\beta 2$-AR expression was higher in oral cavity cancer compared with in other locations. This may be associated with minor salivary glands in the oral cavity, as the autonomic nervous system controls salivation (17). The sympathetic neurotransmitter NE acts via $\beta$-ARs in the salivary gland. The oral cavity tissue has more minor salivary glands than any other head and neck subsites. Therefore, it may be the case that there was higher $\beta 2$-AR expression in oral cavity tissue 

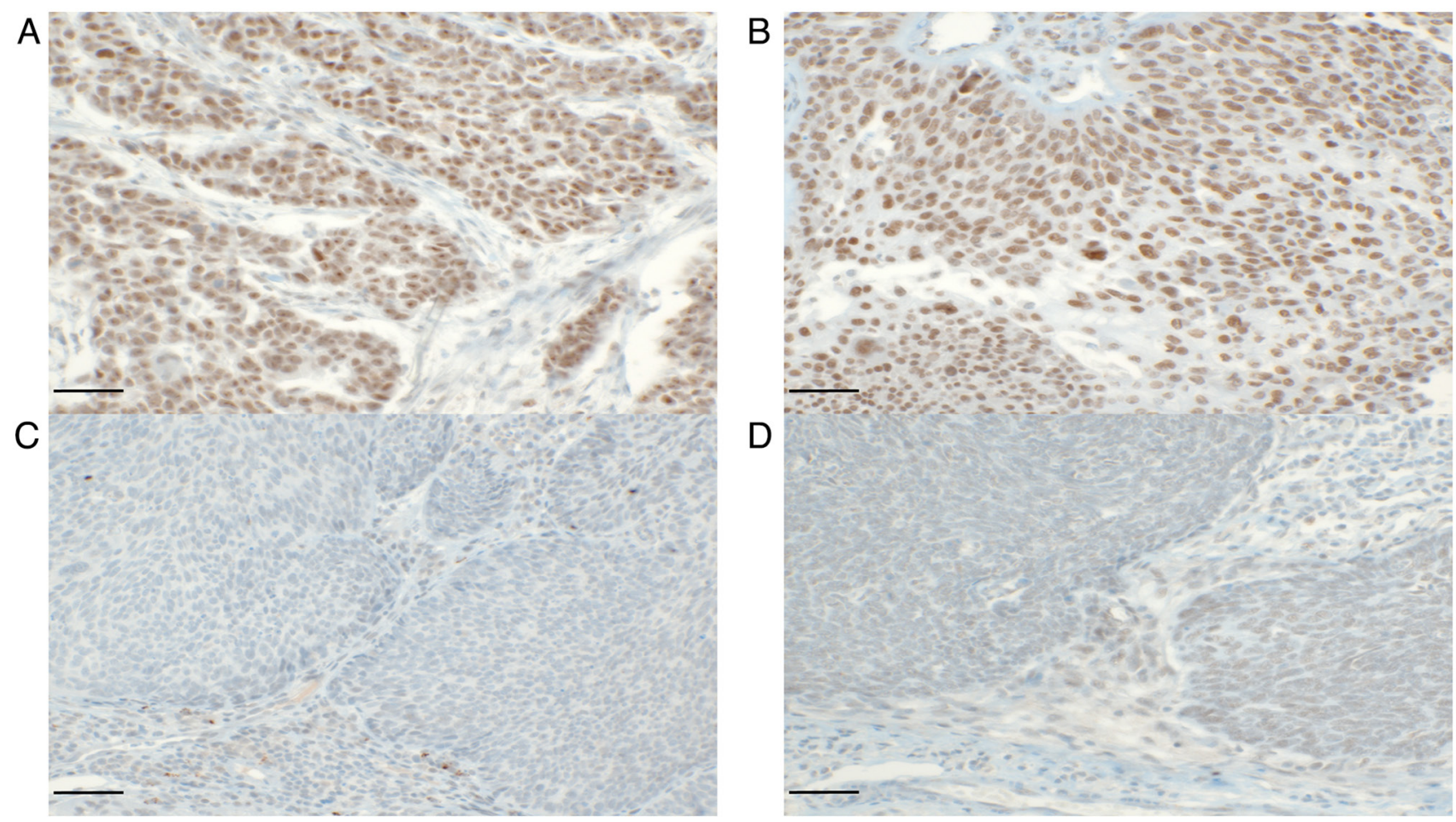

Figure 1. Most head and neck cancer tissues expressed $\beta 2-\mathrm{AR}$, which was notably higher in the oral cavity cancer tissue compared with pharynx cancer tissue. Shown are representative immunohistochemical staining data. (A) Oral cavity cancer tissue. (B) Larynx cancer tissue. (C) Pharynx cancer tissue. (D) Nasal cavity cancer tissue. Scale bar, $0.05 \mathrm{~mm}$. $\beta 2$-AR, $\beta 2$-adrenergic receptor.

A

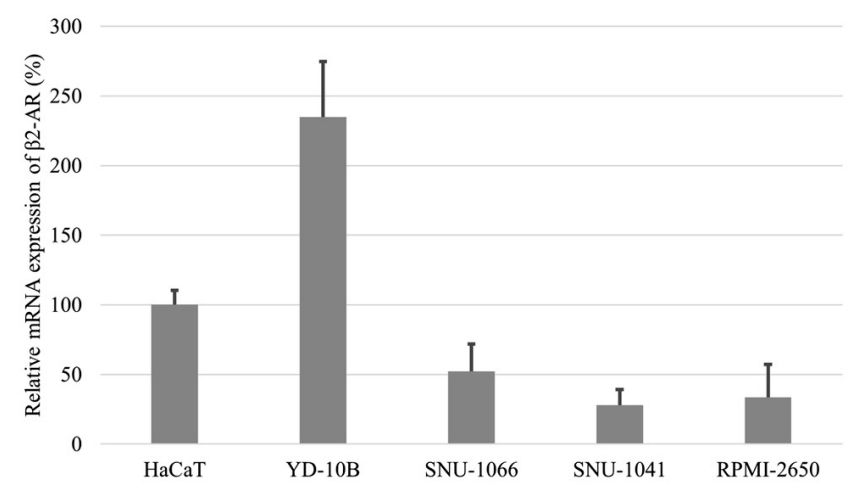

B

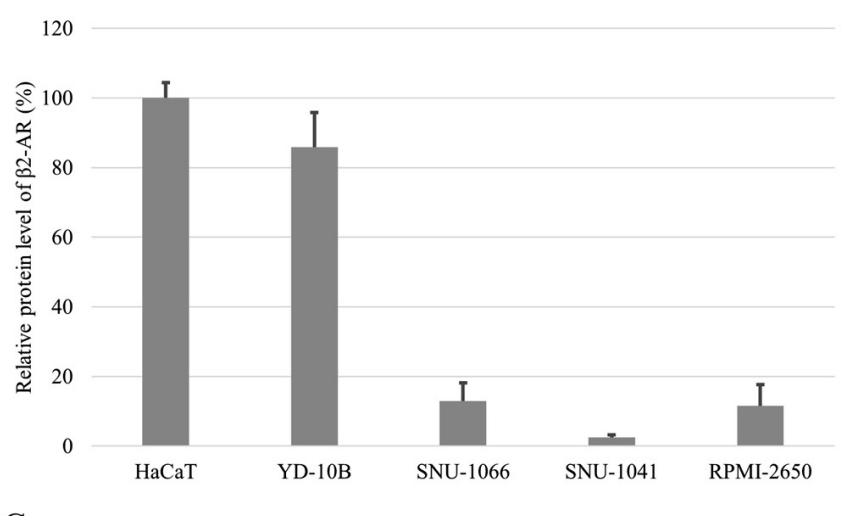

$\mathrm{C}$

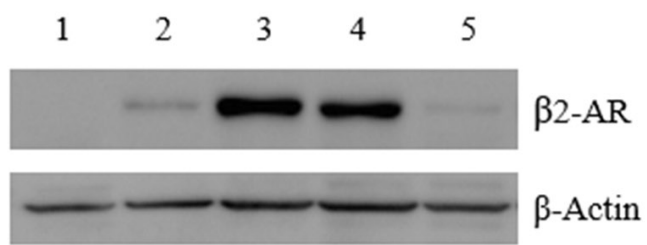

Figure 2. $\beta 2$-adrenergic receptor expression in a normal head and neck cell line, and HNCCLs. (A) Expression of $\beta 2$-AR mRNA in HNCCLs relative to a normal head and neck cell line (HaCaT) assessed via reverse transcription-quantitative PCR. Data are presented mean \pm SD of three different experiments. (B) Expression of $\beta 2$-AR protein in the HNCCLs relative to normal head and neck cell line (HaCaT). Data are presented mean \pm SD of three different experiments. (C) Western blot analysis of $\beta 2$-AR in the HNCCLs. For the western blot analysis, $\beta 2$-AR immunoreactivity was visualized as a single band that migrated at -47 kDa. Lane 1, pharynx cancer cell line, SNU-1041; lane 2, larynx cancer cell line, SNU-1066; lane 3, normal keratinocyte cell line, HaCaT; lane 4, oral cavity cancer cell line, YD-10; and lane 5, nasal cavity cancer cell line, RPMI-2650; HNCCLs, head and neck cancer cell lines.

compared with other subsites. Certain studies have explored the role of $\beta 2$-ARs in head and neck cancer. Bernabé et al (16) demonstrated that $\beta 2$-AR mRNAs were expressed in all 20 oral cavity cancer specimens examined. Furthermore,
Bravo-Calderón et al (17) determined that most of their patients $(77 / 106,72.6 \%)$ with oral cavity cancer had high expression levels of $\beta 2$-AR. Shang et al (11) also reported that 44/65 (67.7\%) oral cavity cancer cases had $\beta 2$-AR expression. 
A

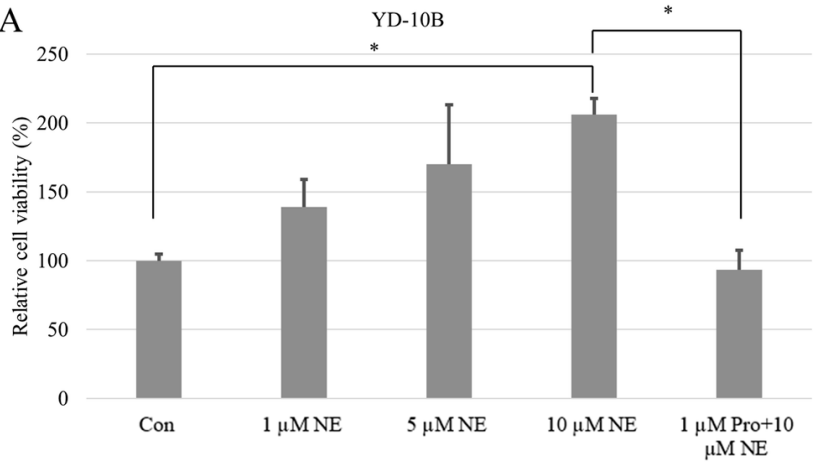

$\mathrm{C}$

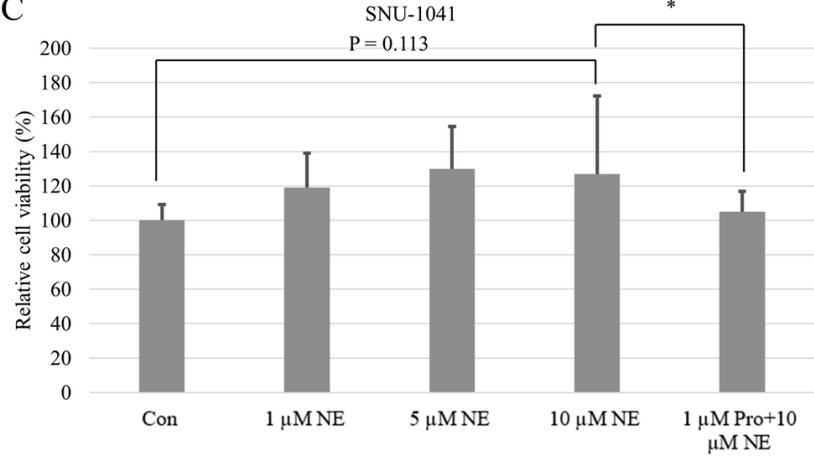

B
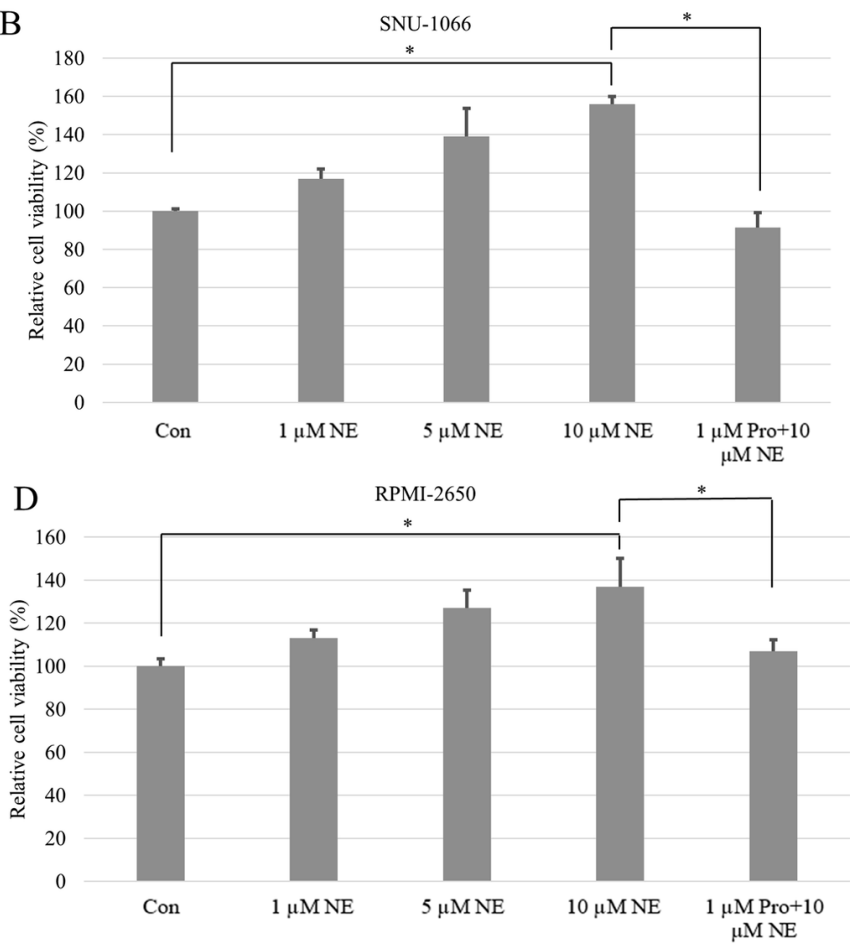

Figure 3. Cell viability in all HNCCLs is stimulated by NE in a dose-dependent manner but is attenuated by $1 \mu \mathrm{M}$ of propranolol. The data from at least three independent experiments are shown. The Con group was not treated with norepinephrine or propranolol. (A) Oral cavity cancer cell line, YD-10B. (B) Larynx cancer cell line, SNU-1066. (C) Pharynx cancer cell line, SNU-1041. (D) Nasal cavity cancer cell line, RPMI-2650. *P<0.05. Con, control; NE, norepinephrine; Pro, propranolol; HNCCLs, head and neck cancer cell lines.

A

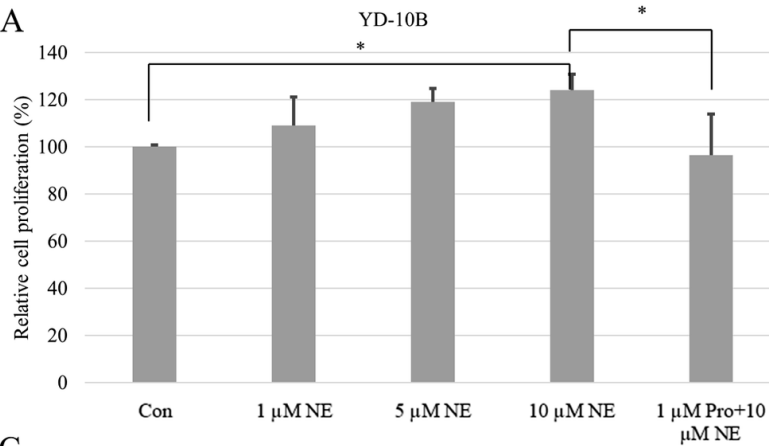

$\mathrm{C}$

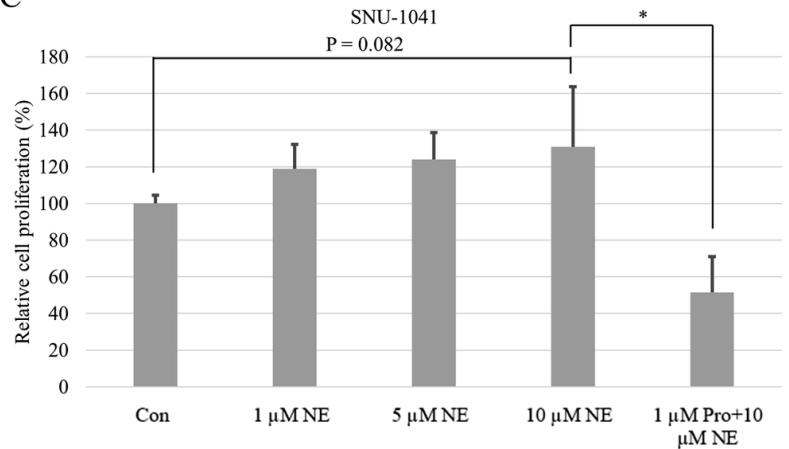

B
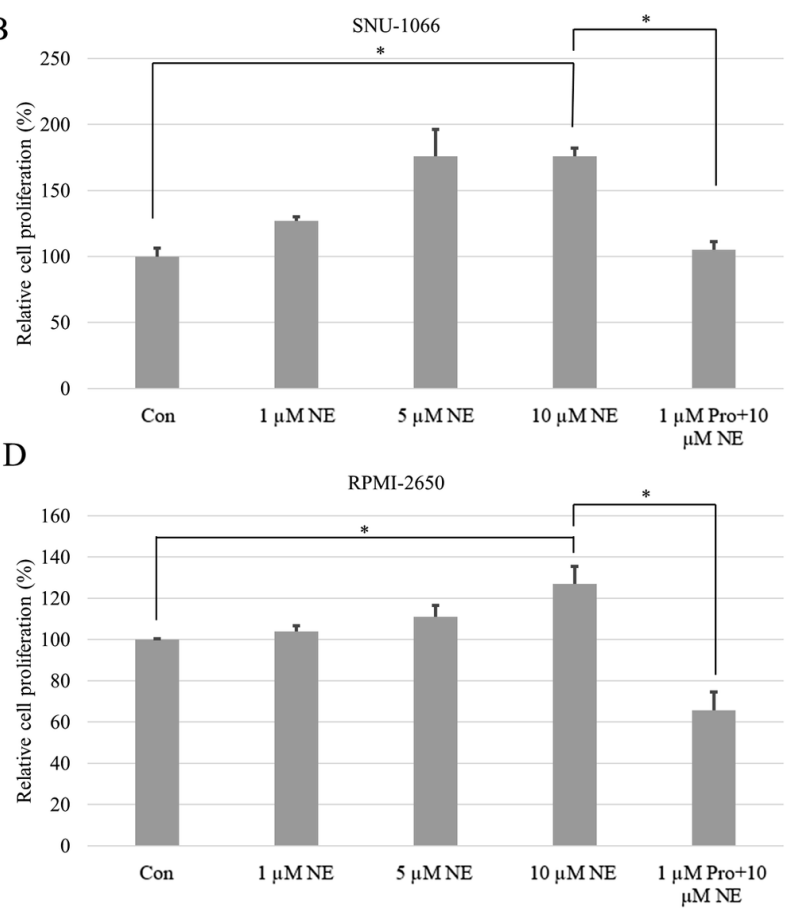

Figure 4. Cell proliferation in all HNCCLs is stimulated by NE dose-dependently and is attenuated by $1 \mu \mathrm{M}$ propranolol. Shown are the data of at least three independent experiments. The Con group was not treated with norepinephrine or propranolol. (A) Oral cavity cancer cell line, YD-10B. (B) Larynx cancer cell line, SNU-1066. (C) Pharynx cancer cell line, SNU-1041. (D) Nasal cavity cancer cell line, RPMI-2650. "P<0.05. Con, control; NE, norepinephrine; Pro, Propranolol; HNCCLs, head and neck cancer cell lines.

However, most of the previous studies regarding $\beta$-AR in head and neck cancer tissues only focused on oral cavity cancer. To the best of our knowledge, the present study was the first to investigate $\beta 2-\mathrm{AR}$ expression in various head and neck cancer tissue types. The current results revealed that, compared with oral cavity cancer, pharyngeal cancer had a relatively 
low expression level of $\beta 2-A R$ and exhibited no significant difference in the cell viability and proliferation after NE and $\beta$-blocker application. This finding is likely due to the presence of different $\beta$-ARs. Most head and neck cancer studies have focused on $\beta 2-\mathrm{AR}$; however, the expression of $\beta 1$ - and $\beta 3-\mathrm{AR}$ in head and neck cancer tissues should also been investigated. There are two main groups of AR; $\alpha$ and $\beta$. In humans, $\beta$-ARs can be subdivided into $\beta 1, \beta 2$ and $\beta 3$. $\beta 1$-ARs are predominantly expressed in the heart, and these account for $70-80 \%$ of the total. The $\beta 2$-ARs are primarily located in lung bronchioles and the arteries of skeletal muscles. Meanwhile, $\beta 3-\mathrm{AR}$ is primarily located in the adipose tissue and participates in regulating lipolysis and thermogenesis (28).

The present results further revealed that NE stimulates the viability and proliferation of the head and neck cancer cells in a dose-dependent manner. NE is the neurotransmitter released during the stress response $(7,18,26,29)$. According to an animal study using a mouse model, chronic stress promoted oral cavity cancer growth, with increased epinephrine and NE levels (19). In addition, Bastos et al (30) demonstrated that NE levels were significantly associated with the severity of anxiety in 93 patients with head and neck cancer. Thus, stress may influence various head and neck cancers.

In the present study, propranolol attenuated the viability and proliferation of head and neck cancer cells. Shang et al (11) observed that propranolol fully inhibited NE-induced mitogen effect. According to the study by Bernabé et al (16) study, NE significantly enhanced cell proliferation and interleukin (IL)-6 expression in oral cavity cancer cell lines (SCC9 and SCC25); however, these effects were inhibited by propranolol, supporting the role of $\beta$-ARs in IL- 6 secretion. In a study by Zhang et al (3) tumor size was significantly different between mice with tongue cancer administered with a selective $\beta 2$-AR blocker and the control group; the $\beta 2$-AR blocker group also had a significantly prolonged survival rate.

In addition to the potential benefits of $\beta$-blockers in cancer treatment, they are considered safe and cost-effective and are already used to treat various other diseases. Numerous patients with head and neck cancer have accompanying cardiovascular diseases and complain of stress and anxiety until they are treated. Thus, after final diagnosis, $\beta$-blockers may be administered up to the time of surgery. This may reduce preoperative anxiety and stress as well as alleviate the aggravation of head and neck cancer caused by psychological factors. Additionally, $\beta$-blockers may be used as an adjunct to radiotherapy or chemotherapy after surgery in various head and neck cancers.

However, the present study had several limitations. Firstly, during the study planning, evaluation of the expression levels of $\beta 1$ - and $\beta 3$-AR was not considered. Moreover, the expression level of $\beta 2-A R$ in normal head and neck tissue was not examined. Further research should aim to investigate the expression of all $\beta$-AR subtypes in normal and cancer cell lines and tissues. Secondly, the selective stimulation of $\beta 1$ - and $\beta 2-A R s$ in cancer cell lines, other than NE, were not assessed. Thus, future studies should also assess selective stimulations of $\beta 1$ - and $\beta 2$-AR. Thirdly, the present study did not evaluate other types of $\beta$-blockers. Propranolol is a non-selective $\beta$-blocker. The effects of $\beta 1$ - and $\beta 2$-selective blockers other than propranolol should also be studied in the future. Fourthly, numerous cell lines were not studied. Only one cell line per anatomic location may be insufficient. Fifth, different approaches for elucidating the related signal pathways must be explored. Sixth, our hypothesis should also be confirmed using animal models. Finally, although we performed the cell membrane invasion assay, we did not include the data in the result. The invasion of all cancer cells were induced by $\mathrm{NE}$ dose-dependently. However, only $1 \mu \mathrm{M}$ of propranolol did not attenuate the invasion ability in any HNCCLs (Figs. S1-S5). If we were able to test the propranolol of different concentrations, we might have had different results.

Despite such limitations, the present study indicated that the stress-related neurotransmitter NE may directly stimulate various head and neck cancers, while $\beta$-blocker treatment may attenuate tumor proliferation in various head and neck cancers.

\section{Acknowledgements}

Not applicable.

\section{Funding}

The present study was supported by the National Research Foundation of Korea (grant no. NRF-2017R1C1B1008842).

\section{Availability of data and materials}

The datasets used and/or analyzed during the current study are available from the corresponding author on reasonable request.

\section{Authors' contributions}

Conceptualization: HGC and SYK. Data curation: KJC, HKK, NJ, and HAS. Formal analysis: MSK. Funding acquisition: MSK. Methodology: JJYJ, KHO, and MSK. Figures: NJ and HAS. Writing - original draft: HAS and MSK. Writing - review and editing: JYJ and MSK. HAS and MSK confirm the authenticity of all the raw data. All authors read and approved the final manuscript.

\section{Ethics approval and consent to participate}

All procedures performed in the present were in accordance with the ethical standards of the institutional research committee and with the 1964 Helsinki declaration and its later amendments or comparable ethical standards. The present study was reviewed and approved by the institutional review board of the CHA Medical Center (IRB no. NON2020-003-002). The need for informed consent was waived for both the use of tissues and medical records because it was practically impossible to obtain consent from the patients retrospectively and the risk to the patients was extremely low, even if they were exempted from consent.

\section{Patient consent for publication}

Not applicable.

\section{Competing interests}

The authors declare that they have no competing interests. 


\section{References}

1. Li P, Zhu K, Mo Y, Deng X, Jiang X, Shi L, Guo C, Zhang W, Zeng Z, Li G, et al: Research Progress of circRNAs in Head and Neck Cancers. Front Oncol 11: 616202, 2021

2. Mehanna H, Hardman JC, Shenson JA, Abou-Foul AK, Topf MC, AlFalasi M, Chan JYK, Chaturvedi P, Chow VLY, Dietz A, et al: Recommendations for head and neck surgical oncology practice in a setting of acute severe resource constraint during the COVID-19 pandemic: An international consensus. Lancet Oncol 21: e350-e359, 2020.

3. Zhang C, Liao X, Ma Z, Liu S, Fang F and Mai H: Overexpression of $\beta$-Adrenergic Receptors and the Suppressive Effect of $\beta(2)$-Adrenergic Receptor Blockade in Oral Squamous Cell Carcinoma. J Oral Maxillofac Surg 78: 1871.e1871-1871.e1823, 2020.

4. Haldar R, Ricon-Becker I, Radin A, Gutman M, Cole SW, Zmora $O$ and Ben-Eliyahu S: Perioperative COX2 and $\beta$-adrenergic blockade improves biomarkers of tumor metastasis, immunity, and inflammation in colorectal cancer: A randomized controlled trial. Cancer 126: 3991-4001, 2020.

5. Chaudhary KR, Yan SX, Heilbroner SP, Sonett JR, Stoopler MB, Shu C, Halmos B, Wang TJC, Hei TK and Cheng SK: Effects of $\beta$-Adrenergic Antagonists on Chemoradiation Therapy for Locally Advanced Non-Small Cell Lung Cancer. J Clin Med 8: 575, 2019.

6. Yap A, Lopez-Olivo MA, Dubowitz J, Pratt G, Hiller J, Gottumukkala V, Sloan E, Riedel B and Schier R: Effect of beta-blockers on cancer recurrence and survival: A meta-analysis of epidemiological and perioperative studies. Br J Anaesth 121: 45-57, 2018.

7. Weberpals J, Jansen L, Carr PR, Hoffmeister M and Brenner H: Beta blockers and cancer prognosis - The role of immortal time bias: A systematic review and meta-analysis. Cancer Treat Rev 47: 1-11, 2016

8. Wolter NE, Wolter JK, Enepekides DJ and Irwin MS: Propranolol as a novel adjunctive treatment for head and neck squamous cell carcinoma. J Otolaryngol Head Neck Surg 41: 334-344, 2012.

9. Silverman DA, Martinez VK, Dougherty PM, Myers JN Calin GA and Amit M: Cancer-Associated Neurogenesis and Nerve-Cancer Cross-talk. Cancer Res 81: 1431-1440, 2021.

10. Zhang B, Wu C, Chen W, Qiu L, Li S, Wang T, Xie H, Li Y, Li C and $\mathrm{Li} \mathrm{L}$ : The stress hormone norepinephrine promotes tumor progression through $\beta 2$-adrenoreceptors in oral cancer. Arch Oral Biol 113: 104712, 2020.

11. Shang ZJ, Liu K and Liang DF: Expression of beta2-adrenergic receptor in oral squamous cell carcinoma. J Oral Pathol Med 38 371-376, 2009

12. Schallreuter KU, Lemke KR, Pittelkow MR, Wood JM, Körner C and Malik R: Catecholamines in human keratinocyte differentiation. J Invest Dermatol 104: 953-957, 1995.

13. Chang PY, Huang WY, Lin CL, Huang TC, Wu YY, Chen JH and Kao CH: Propranolol Reduces Cancer Risk: A Population-Based Cohort Study. Medicine (Baltimore) 94: e1097, 2015.

14. Kim SA, Moon H, Roh JL, Kim SB, Choi SH, Nam SY and Kim SY: Postdiagnostic use of $\beta$-blockers and other antihypertensive drugs and the risk of recurrence and mortality in head and neck cancer patients: An observational study of 10,414 person-years of follow-up. Clin Transl Oncol 19: 826-833, 2017.

15. Sugiura T, Inoue Y, Matsuki R, Ishii K, Takahashi M, Abe M and Shirasuna K: VEGF-C and VEGF-D expression is correlated with lymphatic vessel density and lymph node metastasis in oral squamous cell carcinoma: Implications for use as a prognostic marker. Int J Oncol 34: 673-680, 2009.
16. Bernabé DG, Tamae AC, Biasoli ÉR and Oliveira SH: Stress hormones increase cell proliferation and regulates interleukin-6 secretion in human oral squamous cell carcinoma cells. Brain Behav Immun 25: 574-583, 2011.

17. Bravo-Calderón DM, Oliveira DT, Marana AN, Nonogaki S, Carvalho AL and Kowalski LP: Prognostic significance of beta-2 adrenergic receptor in oral squamous cell carcinoma. Cancer Biomark 10: 51-59, 2011-2012.

18. Vilardi BM, Bravo-Calderón DM, Bernabé DG, Oliveira SH and Oliveira DT: VEGF-C expression in oral cancer by neurotransmitter-induced activation of beta-adrenergic receptors. Tumour Biol 34: 139-143, 2013.

19. Xie H, Li C, He Y, Griffin R, Ye Q and Li L: Chronic stress promotes oral cancer growth and angiogenesis with increased circulating catecholamine and glucocorticoid levels in a mouse model. Oral Oncol 51: 991-997, 2015.

20. Bravo-CalderónDM,Assao A,Garcia NG,Coutinho-CamilloCM, Roffé M, Germano JN and Oliveira DT: Beta adrenergic receptor activation inhibits oral cancer migration and invasiveness. Arch Oral Biol 118: 104865, 2020

21. Yang EV, Sood AK, Chen M, Li Y, Eubank TD, Marsh CB, Jewell S, Flavahan NA, Morrison C, Yeh PE, et al: Norepinephrine up-regulates the expression of vascular endothelial growth factor, matrix metalloproteinase (MMP)-2, and MMP-9 in nasopharyngeal carcinoma tumor cells. Cancer Res 66: 10357-10364, 2006.

22. Doescher J, Veit JA and Hoffmann TK: The 8th edition of the AJCC Cancer Staging Manual: Updates in otorhinolaryngology, head and neck surgery. HNO 65: 956-961, 2017 (In German).

23. Wang B, Gao J, Zhang Q, Fu Y, Liu G, Shi J, Li D, Wang F and Guo H: Diagnostic Value of 68Ga-PSMA PET/CT for Detection of Phosphatase and Tensin Homolog Expression in Prostate Cancer: A Pilot Study. J Nucl Med 61: 873-880, 2020.

24. Bankhead P, Loughrey MB, Fernández JA, Dombrowski Y, McArt DG, Dunne PD, McQuaid S, Gray RT, Murray LJ, Coleman HG, et al: QuPath: Open source software for digital pathology image analysis. Sci Rep 7: 16878, 2017.

25. Livak KJ and Schmittgen TD: Analysis of relative gene expression data using real-time quantitative PCR and the 2(-Delta Delta C(T)) Method. Methods 25: 402-408, 2001.

26. Guo K, Ma Q, Wang L, Hu H, Li J, Zhang D and Zhang M: Norepinephrine-induced invasion by pancreatic cancer cells is inhibited by propranolol. Oncol Rep 22: 825-830, 2009.

27. Yang EV, Kim SJ, Donovan EL, Chen M, Gross AC, Webster Marketon JI, Barsky SH and Glaser R: Norepinephrine upregulates VEGF, IL-8, and IL-6 expression in human melanoma tumor cell lines: Implications for stress-related enhancement of tumor progression. Brain Behav Immun 23: 267-275, 2009.

28. Motiejunaite J, Amar L and Vidal-Petiot E: Adrenergic receptors and cardiovascular effects of catecholamines. Ann Endocrinol (Paris) 82: 193-197, 2021.

29. Patel PR, Hegde ML, Theruvathu J, Mitra SA, Boldogh I and Sowers L: Norepinephrine Reduces Reactive Oxygen Species (ROS) and DNA Damage in Ovarian Surface Epithelial Cells. J Bioanal Biomed 7: 75-80, 2015.

30. Bastos DB, Sarafim-Silva BAM, Sundefeld MLMM, Ribeiro AA, Brandão JDP, Biasoli ÉR, Miyahara GI, Casarini DE and Bernabé DG: Circulating catecholamines are associated with biobehavioral factors and anxiety symptoms in head and neck cancer patients. PLoS One 13: e0202515, 2018.

This work is licensed under a Creative Commons Attribution-NonCommercial-NoDerivatives 4.0 International (CC BY-NC-ND 4.0) License. 